\title{
Decomposition of Bamboo Powder for Eco-Friendly Material Development by Using Superheated Steams
}

\author{
Sayaka Ikeno" ${ }^{1}$, Kiyotaka Obunai ${ }^{2, ~}$, Tadao Fukuta ${ }^{2}$, Koichi Ozaki ${ }^{2}$ \\ ${ }^{1}$ Graduate School of Systems Engineering, Okayama Prefectural University, Okayama, Japan \\ ${ }^{2}$ Department of Systems Engineering, Okayama Prefectural University, Okayama, Japan
}

Email address:

obunai@cse.oka-pu.ac.jp (K. Obunai)

\section{To cite this article:}

Sayaka Ikeno, Kiyotaka Obunai, Tadao Fukuta, Koichi Ozaki. Decomposition of Bamboo Powder for Eco-Friendly Material Development by Using Superheated Steams. Advances in Materials. Special Issue: New Methods of Extraction and Characterization of Plant Fibers.

Vol. 4, No. 5-1, 2015, pp. 1-6. doi: 10.11648/j.am.s.2015040501.11

\begin{abstract}
The purpose of this study is to investigate an alternative method to decompose bamboo for the development of new eco-friendly materials. The effect of superheated steam treatment on the chemistry of decomposed bamboo biomass was investigated; the composition of the decomposed biomass was quantitatively determined, and its molecular structures were also evaluated by IR spectroscopy. The ability of the decomposed bamboo biomass to be molded without the use of binders was also investigated, and the mechanical properties of the molded samples were investigated by a dynamic hardness test. The raw material, consisting of bamboo powder and pure water were put into the reactor and sealed tightly. To decompose the raw material, the temperature of reactor was elevated by the ring furnace to a specified level and maintained for $10 \mathrm{~min}$. After the decomposition, three types of determinations, holocellulose, $\alpha$-cellulose, and lignin determination were performed for quantitative evaluation. The IR spectrum of decomposed bamboo powder was also measured by using FT-IR to evaluate the molecular structure. For investigate the ability of the decomposed bamboo powder to be molded without the use of a binder, the compression molding technique was employed. The young's modulus of molded products was measured by using dynamic hardness tester. Quantitatively determination results revealed that, when the superheated vapor treatment was conducted in the temperature range from 200 to $220^{\circ} \mathrm{C}$, a solid residue containing mostly $\alpha$-cellulose and lignin was obtained. IR spectrum evaluation revealed that the cellulose was decomposed by the superheated steam at $200{ }^{\circ} \mathrm{C}$ and above. The young's modulus of compression molding products also revealed that the lignin contained in the decomposed bamboo powder improved the thermosetting ability after the superheated water vapor treatment. These results suggested that the superheated steam treatment was effective to obtain the decomposed bamboo for the development of new eco-friendly materials.
\end{abstract}

Keywords: Bamboo, Decomposition, Superheated Steam, Compression Molding

\section{Introduction}

Recently, biomass resources have gained increasing attention because of global environmental problems such as the exhaustion of petroleum supplies. For material development, interest has been focused mainly on the woody base biomass. Among the woody base biomass species, bamboo is especially interesting because of its high growth rate and good mechanical characteristics [1-4]. Bamboo has a complex microstructure consisting of cellulose, hemicellulose, and lignin. To develop a new eco-friendly material made from bamboo, the original microstructures must first be decomposed. Alkali treatment methods and steam explosion methods have been utilized to decompose the microstructure of bamboo [5-8]. However, these decomposition methods produce large quantities of toxic waste and also require long treatment times. Moreover, these conventional methods have been utilized to extract only the cellulose from bamboo. The extracted cellulose has been used to reinforce composites with matrices made from other polymers [9-13]. In spite of being a complex bio-based polymer like phenol, the lignin has not been given much previous attention in the development of eco-friendly materials. In order to develop a new eco-friendly material, the usage of lignin as an alternative to other polymers is highly desirable. With these considerations in mind, a new decomposition method using superheated water vapor (steam) has been proposed.

The purpose of this study is to investigate an alternative 
method to decompose bamboo for the development of new eco-friendly materials. The effect of superheated steam treatment on the chemistry of decomposed bamboo biomass was investigated; the composition of holocellulose, $\alpha$-cellulose, and lignin in the decomposed biomass were quantitatively determined, and molecular structures of decomposed bamboo powders were also evaluated by IR spectroscopy. The ability of the decomposed bamboo biomass to be molded without the use of binders was also investigated, and the mechanical properties of the molded samples were investigated by a dynamic hardness test to evaluate the thermosetting ability of decomposed bamboo powder.

\section{Materials and Methods}

\subsection{Raw Material}

The powder-like sawdust of bamboo was obtained from Moso bamboo trees naturally grown in Okayama Japan, with an average age of around four years. Figure 1 shows optical microscopic image of bamboo powder. The longest dimension (length) of the bamboo powder particles was measured for 100 randomly selected samples with an optical microscope. Figure 2 shows the length distribution of the bamboo powders. The mean length of the long side of the bamboo powder was about $0.8 \mathrm{~mm}$. Table 1 shows the amounts of hemi-cellulose, $\alpha$-cellulose and lignin contained in the raw bamboo powder. The raw bamboo powder was dried in the oven to eliminate the moisture.

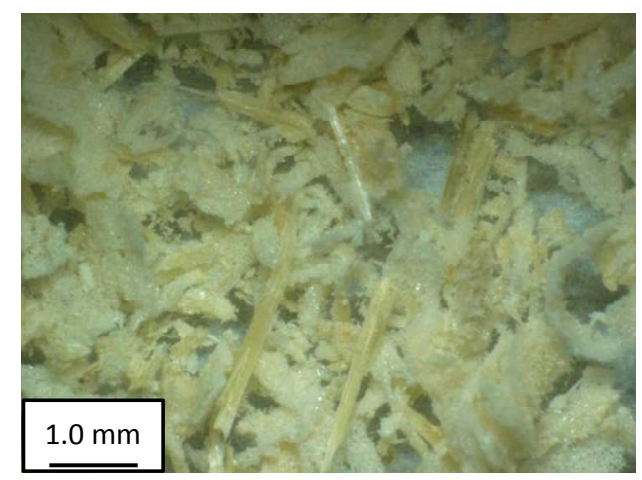

Figure 1. Optical microscopic image of bamboo powder particles.

Table 1. Compositions of raw bamboo powder.

\begin{tabular}{llll}
\hline Hemicellulose & $\alpha$-cellulose & Lignin & Other \\
\hline $28.3 \%$ & $45.5 \%$ & $21.7 \%$ & $4.5 \%$ \\
\hline
\end{tabular}

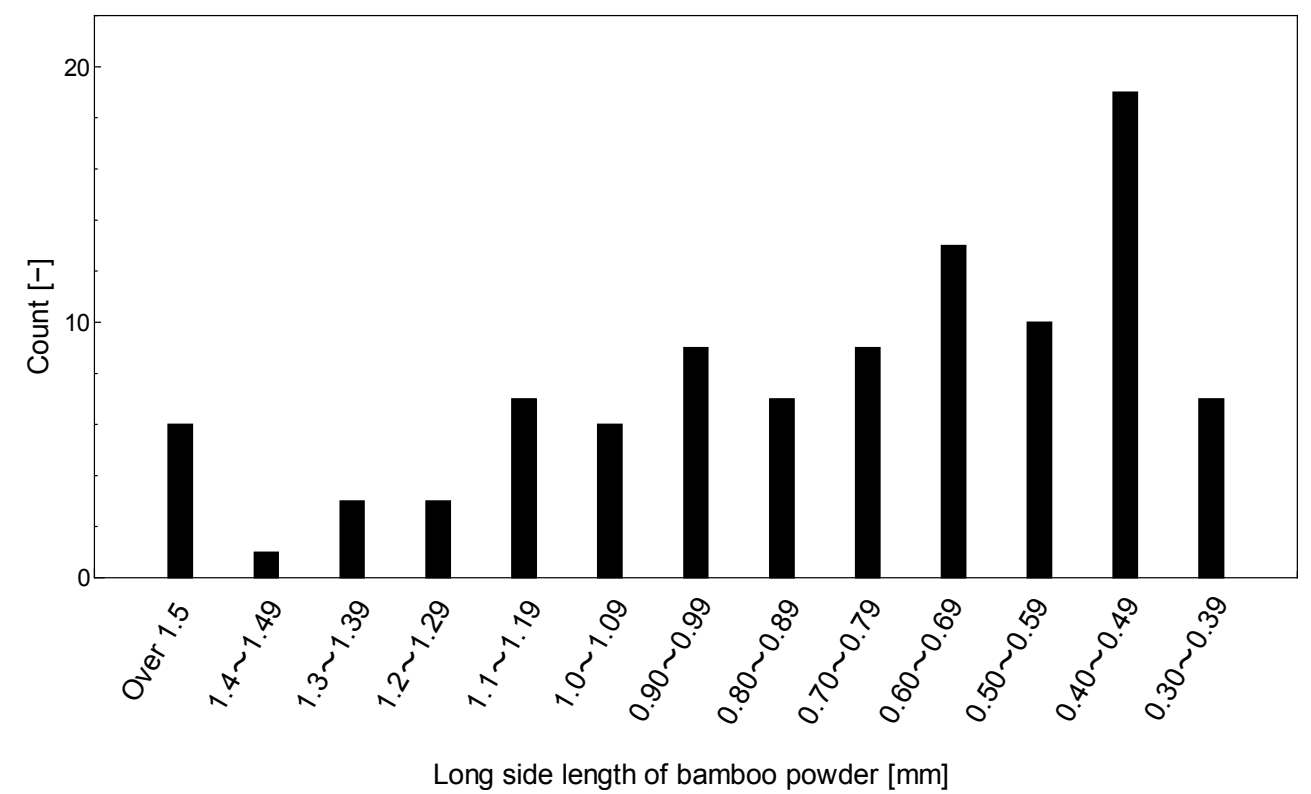

Figure 2. Length distribution of bamboo powder particles.

\subsection{Decomposition of Bamboo Powder}

Figure 3 shows the experimental apparatus used in this study. The experimental apparatus consisted of a subcritical reactor (OM-Labotec:MM-200) and a ring furnace. The raw material, consisting of $15 \mathrm{~g}$ of bamboo powder and $150 \mathrm{cc}$ of pure water were put into the reactor and sealed tightly. To decompose the raw material, the temperature was elevated by the ring furnace to a specified level at constant heating rate of $10^{\circ} \mathrm{C} / \mathrm{min}$, and maintained for $10 \mathrm{~min}$. During the reaction, the pressure in the reactor rose to the saturated vapor pressure of water at the selected temperature. After the decomposition, the reactor was cooled to room temperature at constant cooling rate of $5^{\circ} \mathrm{C} / \mathrm{min}$. A black solid residue and a weakly acid liquid residue, with a $\mathrm{pH}$ around 3.5, were obtained and these were separated by filtration. After filtration, a black solid residue was dried in the oven for $80^{\circ} \mathrm{C}$.

\subsection{Quantitative Determination}

For a quantitative evaluation of the decomposed bamboo powder, three types of determinations, holocellulose, 
$\alpha$-cellulose, and lignin determination were performed on the solid residue. First, the solid residue was de-lignified with sodium chlorite solution to determine the holocelullose content by measuring the weight change during the delignification. Then, hemicellulose was removed from holocelullose by using a $1 \mathrm{~mol} / \mathrm{L} \mathrm{NaOH}$ solution, and the $\alpha$-cellulose content was determined by measuring the weight change due to hemicellulose removal. Finally, the lignin content of the solid residue was determined by subtracting the hemicellulose and $\alpha$-cellulose content from the weight of the decomposed bamboo powder.

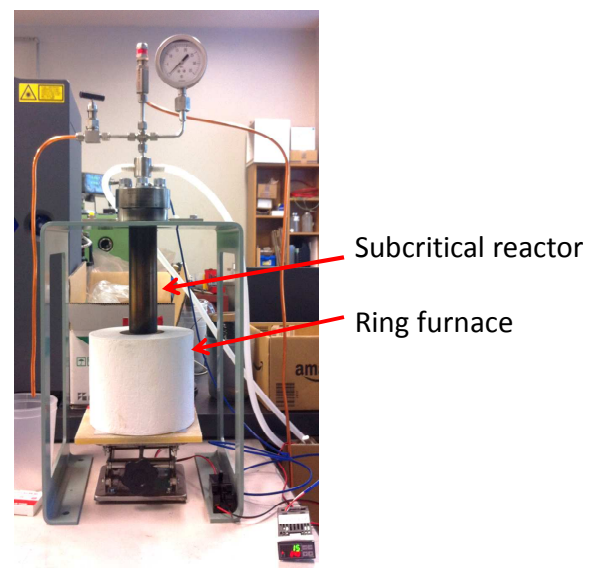

Figure 3. Experimental apparatus.

\subsection{IR Spectrum Measurement}

The IR spectrum was measured to evaluate the molecular structure of decomposed bamboo powder by using FT-IR (JASCO:FT-IR-4100). The $\mathrm{KBr}$ pellet sampling technique was employed to fabricate the test samples. $10 \mathrm{mg}$ of solid residue and $50 \mathrm{mg}$ of $\mathrm{KBr}$ were scraped and evenly mixed by using a mortar. These mixtures were pressed to fabricate the test sample. The measurements were conducted at room temperature. The transmittance of each wavelength was calculated by following equation.

$$
T=\frac{I}{I_{0}}
$$

Here, $I_{0}$ and $I$ denote the intensity of light hitting the sample and light passing through a sample, respectively.

\subsection{Compression Molding}

The ability of the decomposed bamboo to be molded without the use of a binder was investigated by using a compression molding technique. The $7 \mathrm{~g}$ of decomposed solid residue, whose treatment temperature had been $220^{\circ} \mathrm{C}$, was put into the stainless steel mold illustrated in figure 4 , with 20 cc of ethanol as a solvent and pressed for $30 \mathrm{~min}$. To investigate the effect of superheated water vapor treatment on the molding ability, raw bamboo powder was also prepared for molding. In order to evaluate the thermosetting ability of the materials, the two types of molding conditions in which mold temperature was different were tested. At cold molding, molding was conducted by using cold mold of room temperature of $25^{\circ} \mathrm{C}$ and pressed for $30 \mathrm{~min}$. At hot molding, the molding was conducted by using hot mold of $150^{\circ} \mathrm{C}$ and pressed for $30 \mathrm{~min}$. Here, the mold temperature was elevated from room temperature to $150^{\circ} \mathrm{C}$ at constant heating rate of $10^{\circ} \mathrm{C} / \mathrm{min}$. then mold was closed and molding pressure was applied by hydraulic press for $30 \mathrm{~min}$. After pressing, mold was cooled to room temperature at constant cooling rate of $30^{\circ} \mathrm{C} / \mathrm{min}$.

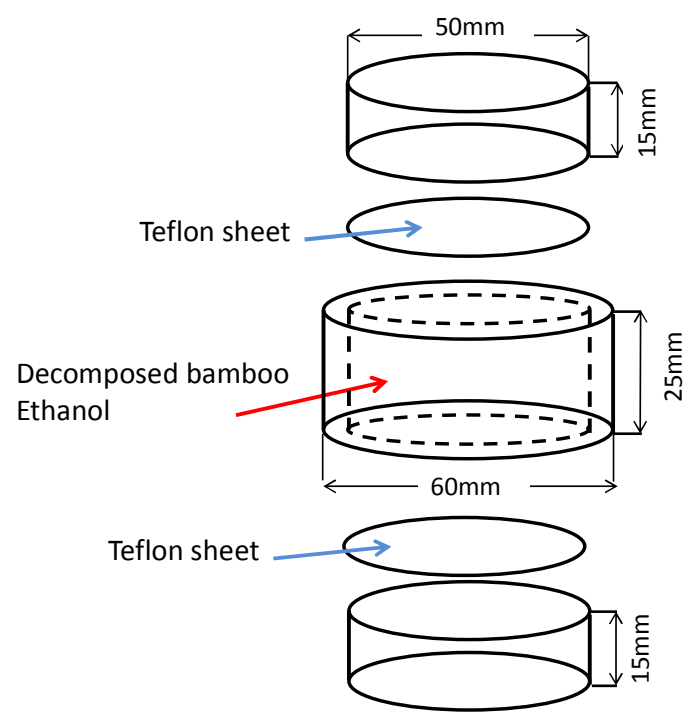

Figure 4. Mold for compression molding.

\subsection{Micro Hardness Test}

The mechanical properties of the molded products were characterized by using a dynamic hardness tester (SHIMADZU: DUH-200) shown in figure 5. The indentation force was applied to the surface of molded products by a diamond indenter until the reaction force increased to $9.8 \mathrm{mN}$ while maintaining a constant rate of force increase of 1.42 $\mathrm{mN} / \mathrm{s}$. The maximum load was held for $5 \mathrm{~s}$ and then released to zero at $1.42 \mathrm{mN} / \mathrm{s}$ rate for force decrease in the opposite direction. During this test, the stroke of the indenter and applied force were measured. Young's modulus of the molded products was characterized by analyzing the slope of applied force-stroke curve during unloading. The Young's modulus at the surface of the molded products was measured at 16 or more different points, and then averaged.

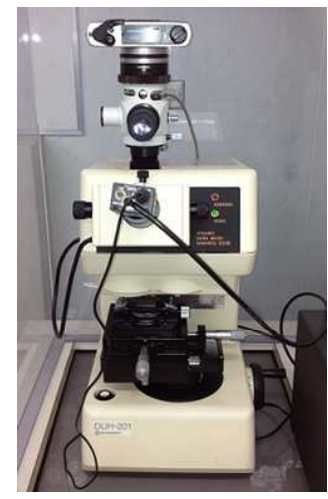

Figure 5. Dynamic hardness tester. 


\section{Results and Discussions}

\subsection{Composition of Decomposed Bamboo Powder}

Figure 6 shows the normalized weight change of hemi-cellulose, $\alpha$-cellulose, and lignin as a function of the temperature of the superheated water vapor. Test results showed that the hemi-cellulose decomposition began at around $170^{\circ} \mathrm{C}$ and was almost completed at around $200^{\circ} \mathrm{C}$. The $\alpha$-cellulose decomposition began at $220^{\circ} \mathrm{C}$ and was almost completed at about 250 to $260^{\circ} \mathrm{C}$. On the other hand, the decomposition of lignin was not observed by superheated steam treatment even at $300^{\circ} \mathrm{C}$. These results revealed that when the superheated vapor treatment was conducted in the temperature range from 200 to $220^{\circ} \mathrm{C}$, a solid residue containing mostly $\alpha$-cellulose and lignin was obtained. These result suggested that, compared to other decomposed method, such as alkali treatment that would extract only $\alpha$-cellulose, our proposed method could extract a $\alpha$-cellulose and lignin mixture and these ratio could easily controlled by changing the processing temperature. Moreover, no toxic waste was exhausted by our proposed method.

\subsection{IR Spectrum of Decomposed Bamboo Powder}

Figure 7 shows the typical IR spectrum of raw and decomposed bamboo powders. For visibility, the IR spectrum of each samples were plotted with offset. In order to evaluate the state of decomposition of cellulose, the peak near 1030 $\mathrm{cm}^{-1}$, which originates in a $\mathrm{C}-\mathrm{O}$ expansion vibration, was studied. Figure 8 shows the IR transmittance of the IR-band originating in the $\mathrm{C}-\mathrm{O}$ expansion vibration as a function of the temperature of the superheated vapor. This graph shows that the transmittance originating in cellulose was almost constant until the superheated steam temperature reached $200{ }^{\circ} \mathrm{C}$, and then the transmittance increased significantly as the temperature rose from 200 to $300^{\circ} \mathrm{C}$. This result demonstrates that cellulose was decomposed by the superheated steam at $200^{\circ} \mathrm{C}$ and above, which is the same tendency that was discussed in the previous section.

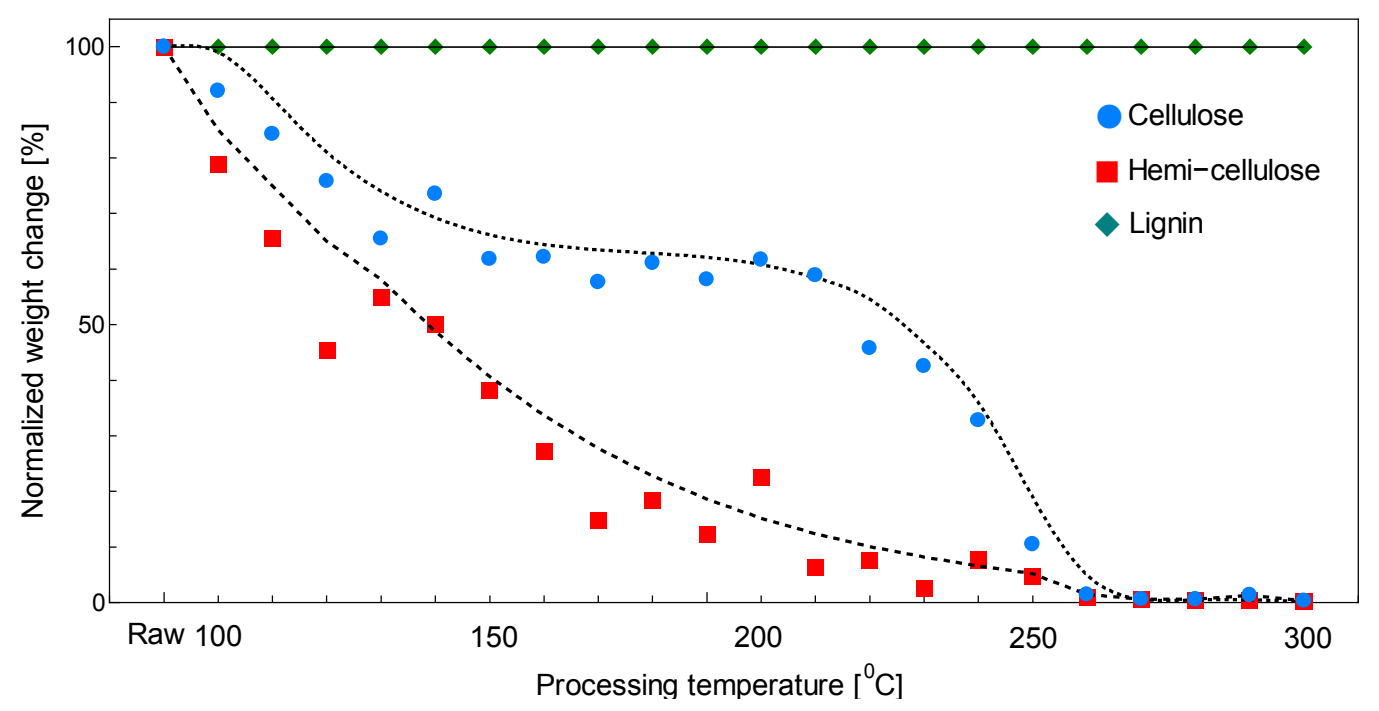

Figure 6. Normalized weight change of hemicellulose, $\alpha$-cellulose, and lignin.

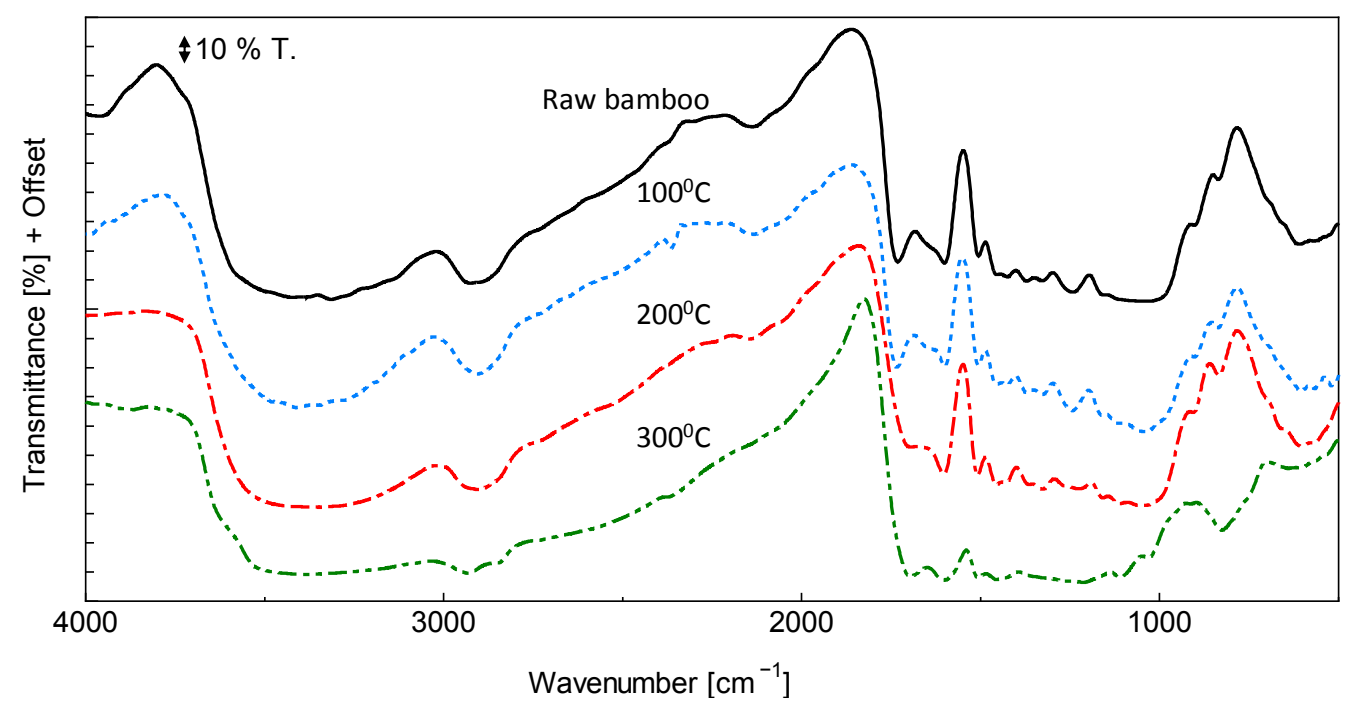

Figure 7. IR spectra of raw and decomposed bamboo powders. 


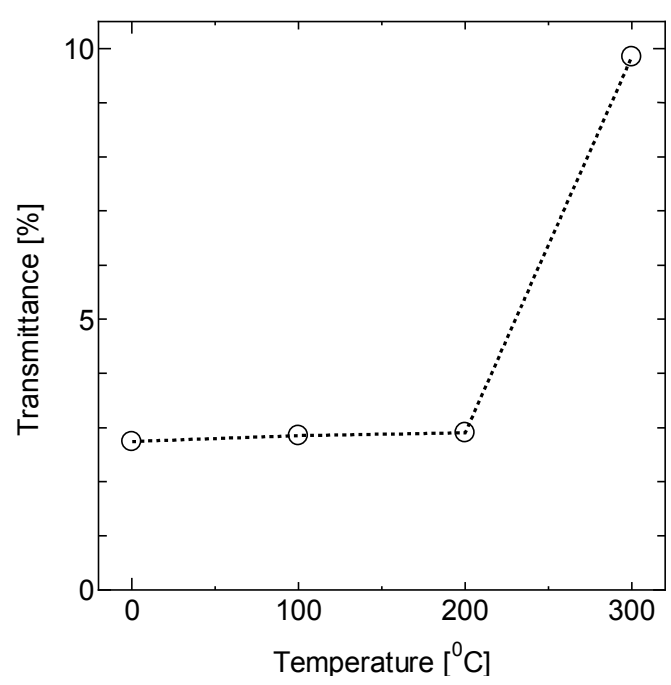

Figure 8. IR transmittance of $C$-O expansion vibration.

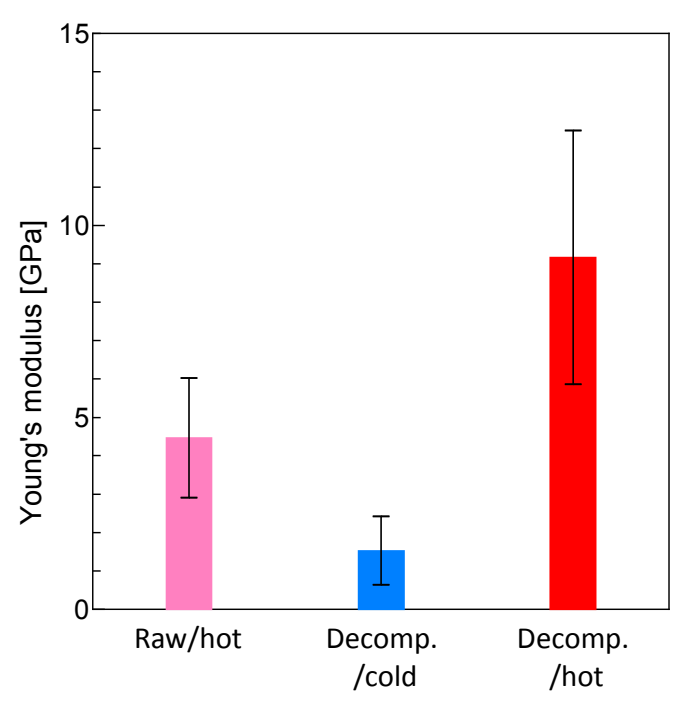

Figure 9. Young's modulus of the surface of molded products.

\subsection{Mechanical Characteristics of Molded Products}

By conducting the compression molding with decomposed bamboo powder, solid molded product was obtained. On the other hand, when using raw bamboo powder, the obtained product was highly brittle. Figure 9 shows the Young's modulus of the surface of cold or heat pressed molded products made from raw or decomposed bamboo powder. Here, the hardness of the cold pressed molded products made from raw bamboo powder was insufficient for testing, and so the graph was omitted. Test results showed that the Young's modulus of the molded products was increased by superheated steam treatment. Compared to Young's modulus of the heat pressed molding products, that of the cold pressed molding products was low. Moreover, the Young's modulus of heat pressed molded products made from decomposed bamboo powder was higher than that made from raw bamboo powder. These results suggest that the lignin contained in the decomposed bamboo powder improved the thermosetting ability after the superheated water vapor treatment.

\section{Conclusions}

In this study, the state of decomposition of the bamboo by superheated steam and thermosetting ability of decomposed bamboo powder were investigated, and the following conclusions were drawn.

1. When the superheated vapor treatment was conducted in the temperature range from 200 to $220^{\circ} \mathrm{C}$, a solid residue containing mostly $\alpha$-cellulose and lignin was obtained.

2. IR spectrum evaluation revealed that the cellulose was decomposed by the superheated steam at $200{ }^{\circ} \mathrm{C}$ and above.

3. The lignin contained in the decomposed bamboo powder improved the thermosetting ability after the superheated water vapor treatment.

\section{References}

[1] S.H. Li, Q.Y. Zeng, Y.L. Xiao, S.Y. Fu, B.L. Zhou, "Biomimicry of bamboo bast fiber with engineering composite materials", Materials Science and Engineering, C 3 (1995) 125-130.

[2] S. Amada, Y. Ichikawa, T. Munekara, Y. Nagase and H. Shimizu, Fiber texture and mechanical graded structure of bamboo, Composites Part B, 28B (1997), 13-20.

[3] J.M.O. Scurlocka, D.C. Dayton and B. Hames, Bamboo: an overlooked biomass resource? , Biomass Bioenergy 19 (2000) 229-244.

[4] Khosrow Ghavami,"Bamboo as Reinforcement in structural concrete elements", Cement \& Concrete Composites, 27 (2005) 637-649.

[5] K. Okubo, T. Fujii and N. Yamashita, Improvement of interfacial adhesion in bamboo polymer composite enhanced with microfibrillated cellulose, JSME International Journal Series A Solid Mechanics Material Engineering, 48 (2005) 199-204.

[6] M. Dasm D. Chakraborty, Influence of alkali treatment on the fine structure and morphology of bamboo fibers, Journal of Applied Polymer Science, 102 (2006) 5050-5056

[7] R. Tokoro, D. M. Vu, K. Okubo, T. Tanaka, T. Fujii and T. Fujiura, How to improve mechanical properties of polylactic acid with bamboo fibers, Journal of Materials Science, 43 (2008) 775-787.

[8] S. Suzuki, K. Okubo and T. Fujii, Development of high strength bamboo paper using parenchyma cells, High Performance Structures and Materials IV, (2008) 241-249.

[9] Jain S, Kumar R, Jindal UC. Development and fracture mechanism of the bamboo/polyester resin composite, Journal of Materials Science Letters, 12 (1993) 558-560.

[10] Chen X, Guo Q, Mi Y. Bamboo fibre-reinforced polypropylene composites: a study of the mechanical properties. Journal of Applied Polymer Science, 69 (1998) 1891-1899. 
[11] H. J. Kim, D. W. Seo, J. K. Kim and T. Fujii, Tensile properties and water absorption behavior of bamboo fiber reinforced composites, Key Engineering Materials, 306-308 (2006) 417-422.

[12] M. Das, A. Pal and D. Chakraborty, Effects of mercerization of bamboo strips on mechanical properties of unidirectional sbamboo-novolac composites, Journal of Applied Polymer Science, 100 (2006) 238-244.

[13] Yeng-Fong Shih, Mechanical and thermal properties of waste water bamboo husk fiber reinforced epoxy composite, Materials Science and Engineering A, 445-446 (2007) 289-295. 